\title{
BIOPROTEÇÃO DE LINGÜIÇA DE FRANGO ${ }^{1}$
}

\author{
Liana Inês Guidolin MILANI², Leadir Lucy Martins FRIES², Patrícia Bisso PAZ²,
}

\author{
Maíra BELLÉ2 ${ }^{2}$, Nelcindo Nascimento TERRA ${ }^{2, *}$
}

\section{RESUMO}

O presente trabalho teve como objetivo utilizar culturas bioprotetoras para inibir o desenvolvimento de microrganismos indesejáveis, na elaboração de lingüiça de frango com boas características sensoriais, durante seu periodo de armazenamento a $8^{\circ} \mathrm{C}$. As lingüiças de frango foram elaboradas partindo da mesma massa básica (controle), e adicionando a cultura Elce e as culturas Bactoferm B2 e a Bactoferm S-SX. As análises realizadas foram: contagem de bactérias láticas, contagem de microrganismos psicrotróficos, contagem de Gram negativos, contagem de Staphylococcus aureus e contagem de Clostridios Sulfitos Redutores; análise sensorial e determinação de pH. Não houve desenvolvimento de Staphylococcus aureus e Clostridios Sulfitos Redutores. Alta contagem de bactérias láticas foi observada nas amostras de lingüiça de frango tratadas, devido à adição das culturas bioprotetoras. O pH destas, manteve-se com valores ligeiramente inferiores as lingüiças controle. Entretanto, as lingüiças de frango tratadas com a cultura Elce apresentaram menor desenvolvimento de microrganismos Gram negativos, sendo que no final do periodo de armazenamento a contagem estava aproximadamente dois ciclos logaritmicos inferior as do controle, indicando que o emprego desta cultura bioprotetora contribuiu para uma melhor qualidade microbiológica deste produto cárneo. As amostras tratadas com a cultura Bactoferm B2 e Bactoferm S-Sx apresentaram uma pequena inibição microbiana em relação ao controle, enquanto que a cultura Elce apresentou maior ação antimicrobiana. As culturas bioprotetoras melhoraram as características sensoriais das lingüiças de frango cruas, quando comparadas ao controle. Depois de serem assadas essas diferenças não foram observadas.

Palavras-chave: lingüiça de frango; bioproteção; culturas "starters"

\section{SUMMARY}

CHICKEN SAUSAGES BIOPROTECTION. To inhibit the undesirable microorganisms as well as to obtain better sensorial characteristics, bioprotective cultures were used on chicken sausages production. The chicken sausages were elaborated from a basic mixture (control) and by adding either the Elce or Bactoferm B2 plus Bactoferm S-Sx, which were kept under $8^{\circ} \mathrm{C}$ during its storage period. Lactic acid bacteria, psychotropic microorganisms, Gram negative counts, sensorial and the $\mathrm{pH}$ analysis were done. It was not observed the Staphylococcus aureus and sulfite-reducing clostridia growth, although the lactic acid bacteria were high on the treated samples, due to the addition of the bioprotective cultures. It was observed that the addition of Elce culture lowered the Gram-negative growth by two logarithmic cycles compared to the controls at the end of the storage period. The samples treated with Bactoferm B2 plus Bactoferm SSx showed a slight Gram negative bacteria inhibition compared to the control samples. The addition of bioprotective culture improved the sensorial characteristics of the raw chicken sausages, although when the samples were cooked the differences were not observed. Therefore, the Elce culture showed a better microbial protection giving a better microbial quality for the meat product and overall, the bioprotective cultures presented better sensorial characteristics than the control samples.

Keywords: chicken sausage; bioprotection; starter cultures.

\section{1 - INTRODUÇÃO}

Desde remota antigüidade o homem vem fabricando diferentes tipos de lingüiças, na busca de conservar a carne e fornecer um produto à altura das aspirações do consumidor [18]. No Brasil, a lingüiça é um dos produtos cárneos mais fabricados (250.000t em 1994), provavelmente porque sua elaboração, além de não exigir tecnologia sofisticada, utiliza poucos equipamentos e que são de baixo custo $[9,18]$.

Na fabricação da lingüiça, a matéria-prima é moída tornando-se imprópria para o consumo muito rapidamente, pois aumenta a superficie de exposição para a contaminação e o crescimento de microrganismos [14, 15]. Além disso, a lingüiça por ser um produto frescal, não sofre nenhum tratamento térmico que reduza a microbiota, possui também elevada atividade de água, tendo então uma vida-útil curta, a qual está diretamente ligada à carga microbiana resultante das diferentes contaminações, ape-

1. Recebido para publicação em 01/06/2001. Aceito para publicação em 09/10/2002 (000666).

Departamento de Tecnologia e Ciência de Alimentos, CCR, Universidade Federal de Santa Maria CEP:97105-900 - Santa Maria - RS - Brasil.

* A quem a correspondência deve ser enviada. sar da utilização do frio [18]. A coloração das lingüiças que deve ser vermelha, atraente muitas vezes, é conseguida por adição de curas especiais baseadas especialmente em altos teores de sais de cura e acidez. Entretanto, as opiniões atuais sobre os sais de cura têm levado ao uso de quantidades consideravelmente menores [15].

As lingüiças do tipo frescal são alimentos grandemente expostos à contaminação e representam um excelente meio para a multiplicação de microrganismos. As prováveis fontes de contaminação compreendem as carnes, as tripas ou envoltórios, os temperos ou condimentos, bem como a água utilizada em todas as aplicações de limpeza e manutenção [11]. Segundo TERRA [18], os defeitos mais comuns em lingüiças de frango são de origem microbiana, devido à carne mecanicamente separada de frango adicionada a massa.

O uso alternativo de barreiras adicionais para prevenir o desenvolvimento microbiano em alimentos refrigerados tem sido recomendado. Uma barreira que é bem aceita pelos consumidores por ser "natural" e benéfica para a saúde é o uso da bioconservação $[10,12]$.

As culturas "starters" podem contribuir aumentando a segurança e atratividade sensorial dos produtos. 
Podem fornecer também niveis elevados e constantes de qualidade e vida-de-prateleira [7].

Portanto, o presente trabalho teve como objetivo utilizar culturas bioprotetoras para inibir o desenvolvimento de microrganismos indesejáveis na elaboração de lingüiça de frango com características sensoriais agradáveis e atraentes durante seu período de armazenamento a $8^{\circ} \mathrm{C}$.

\section{2 - MATERIAL E MÉTODOS}

\section{1 - Elaboração das lingüiças de frango}

Para a elaboração das lingüiças foi utilizada a seguinte formulação básica:

TABELA 1. Formulação básica das lingüiças de frango.

\begin{tabular}{lc}
\hline \multicolumn{1}{c}{ Matéria-Prima } & Quantidade(kg) \\
\hline Frango desossado & 44,75 \\
Toucinho & 7,08 \\
Pele de frango & 25,49 \\
Coxa desossada com pele & 22,68 \\
\hline \multicolumn{1}{c}{ Ingredientes } & \\
\hline Água & $11,33 \mathrm{~L}^{*}$ \\
Proteimax & 11,33 \\
Condimento & 1,13 \\
Sal comum & 1,41 \\
Pó húngaro $\left(^{*}\right)$ & 0,84 \\
Polifosfato & 0,38 \\
Eritorbato de Sódio & 0,084 \\
Gelmax $\left(^{*}\right)$ & 1,41 \\
Biored $\left(^{*}\right)$ & 0,028 \\
\hline
\end{tabular}

${ }^{*} \mathrm{~L}=$ litros

A matéria-prima foi moída e homogeneizada com os demais ingredientes. A partir desta massa obteve-se um lote de lingüiça controle e outros dois com diferentes culturas bioprotetoras.

\subsection{1 - Lingüiça de frango controle}

A massa obtida anteriormente foi embutida em tripa natural de suino, posteriormente acondicionadas em embalagens de polietileno com aproximadamente $1 \mathrm{~kg}$ por pacote.

\subsection{2 - Linguiiça de frango adicionada da cultura Elce}

A massa básica de lingüiça de frango foi adicionada de 4,8g de cultura Elce BR 100 (TEXEL $\AA)$ e $80 \mathrm{~g}$ de glicose para cada $40 \mathrm{~kg}$. Foi embutida e embalada da mesma forma que as controle. A cultura Elce é composta de
Lactobacillus sake, Pediococcus pentosaceus, Staphylococcus xylosus II, Staphylococcus carnosus e Debaryomyces hansenii.

\subsection{3 - Lingüiça de frango adicionada de Bactoferm B2 e Bactoferm S-SX}

Homogeneizou-se 40kg da massa básica para lingüiça de frango com $12 \mathrm{~g}$ de Bactoferm B2(Chr. Hansen $\left.{ }^{\circledR}\right)$ e $12 \mathrm{~g}$ de Bactoferm S-SX (Chr. Hansen $\left.{ }^{\circledR}\right)$, contendo Lactobacillus alimentarius e Staphylococcus xylosus, respectivamente. Foram embutidas e embaladas da mesma forma que o controle.

\section{2 - Plano de Amostragem}

As lingüiças adicionadas das culturas bioprotetoras e as controle foram armazenadas a $8^{\circ} \mathrm{C}\left( \pm 1^{\circ} \mathrm{C}\right)$ e a cada três dias realizadas análises microbiológicas, determinação do pH e análise sensorial. Para cada dia de análise utilizou-se uma embalagem de $1 \mathrm{~kg}$, sendo que de cada uma delas foram realizadas análises em triplicata.

\section{3 - Análises microbiológicas}

As análises microbiológicas realizadas foram a contagem de Bactérias Láticas, utilizando Agar MRS [17], microrganismos Gram negativos [8], microrganismos psicrotróficos, Staphylococcus aureus e clostridios ou clostridia sulfito redutores [3].

\section{4 - Análise sensorial}

A análise sensorial foi realizada por um painel de 7 pessoas não-treinadas através de uma ficha de avaliação, utilizando uma escala hedônica de 0,0 a 10,0 para avaliar o produto cárneo assado $\left(250^{\circ} \mathrm{C}\right.$ por 1,5 horas $)$ quanto a cor, aroma, sabor, textura e aparência e o produto cru quanto a cor, aroma e aparência. O valor 10,0 representava um produto de total aceitabilidade onde o provador gostou muitíssimo e 0,0 um produto inaceitável onde o provador não gostou muitíssimo [13].

\section{5 - Determinação do pH}

$\mathrm{O}$ pH foi determinado com medidor de $\mathrm{pH}$ DIGIMED ${ }^{\circledR}$ em um homogeneizado de 10 gramas da amostra com $100 \mathrm{ml}$ de água deionizada [2].

\section{6 - Análise estatística}

Os dados obtidos foram submetidos à Análise de Variância, utilizando o programa Sigma Plot para o pH e dados microbiológicos e o programa Statgraf para a análise sensorial, considerando o nivel de significância de $\mathrm{p}<0,05$.

\section{3 - RESUlTADOS E DISCUSSÃo}

O conhecimento das propriedades dos microrganismos podem contribuir para a redução de riscos higiênicos, não somente no campo clássico de aplicação do "starter", mas também em novos campos onde eles po- 
dem ser empregados como culturas de proteção, os quais inibem o desenvolvimento de microrganismos patogênicos ou mesmo deteriorantes nos alimentos [7].

A contagem de bactérias láticas (Figura 1) apresentou-se mais elevada no inicio do periodo analisado nas lingüiças de frango tratadas uma vez que as mesmas foram adicionadas de culturas bioprotetoras. Verifica-se que nas amostras controle, a contagem de bactérias láticas aumentou rapidamente atingindo valores superiores a $10^{7} \mathrm{UFC} / \mathrm{g}$ no $6^{\circ}$ dia de armazenamento. Foi também observado como conseqüência uma elevação muito rápida na contagem de microrganismos psicrotróficos (Figura 2). Sabe-se que contagens microbiológicas elevadas, acima de $10^{6} \mathrm{UFC} / \mathrm{g}$, indicam que o produto cárneo encontra-se em condições insatisfatórias para o consumo [5]. No entanto, quando são adicionadas culturas, este limite não pode ser considerado, devido ao fato de ter-se adicionado niveis elevados de microrganismos bioprotetores.

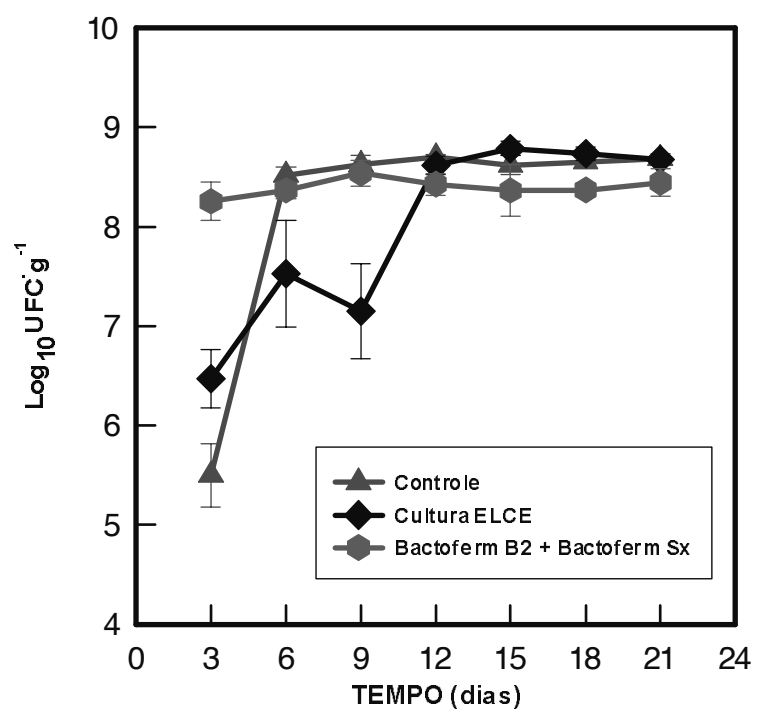

FIGURA 1. Contagem de bactérias lácticas de lingüiça de frango, com ou sem a adição de culturas, durante o período de armazenamento $\left(8^{\circ} \mathrm{C}\right)$.

O armazenamento de carnes e produtos cárneos refrigerados, recobertos com película permeável ao oxigênio, origina um elevado potencial redox na superficie da carne, apropriado para o desenvolvimento de microrganismos aeróbios psicrotróficos. Os bacilos Gram-negativos crescem rapidamente nestas condições, podendo ser responsáveis pelas alterações que se desenvolvem [1]. Devido a este fato foi acompanhado o desenvolvimento de tais microrganismos.

Nas amostras de lingüiça que foram adicionadas das culturas bioprotetoras observou-se menor desenvolvimento de bactérias Gram negativas (Figura 3). A cultura Elce demonstrou ação antagonista frente as bactérias Gram negativas, uma vez que estes microrganismos apresentaram um pequeno desenvolvimento no início do armazenamento diminuindo com o passar do tempo. A contagem de Gram negativos nas lingüiças de frango adiciona- das da cultura Elce, passou a ser significativamente inferior às amostras controle a partir do 9o dia de armazenamento e no final do período analisado estava 2,3 ciclos logaritmicos abaixo das amostras controle, indicando desta forma que o emprego desta cultura bioprotetora contribuiu para uma melhor qualidade microbiológica deste produto cárneo. Já as lingüiças de frango adicionadas da cultura Bactoferm B2 e Bactoferm S-Sx apresentaram uma pequena inibição em relação ao controle, sendo que apresentaram valores que diferiram do controle apenas no $9^{\circ}$ dia de armazenamento (Figura 3).

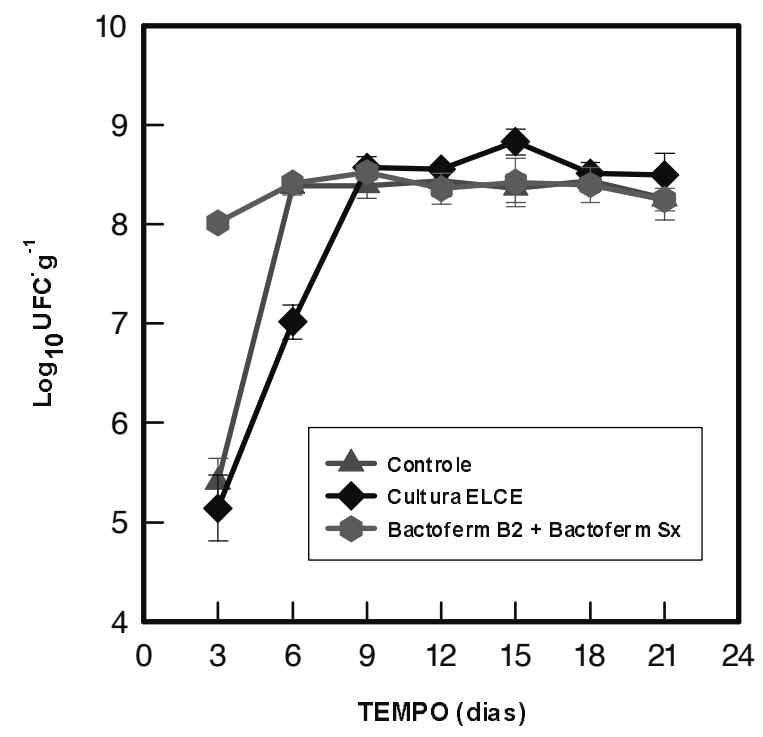

FIGURA 2. Contagem de microorganismos psicotróficos de lingüiça de frango, com ou sem a adição de culturas, durante

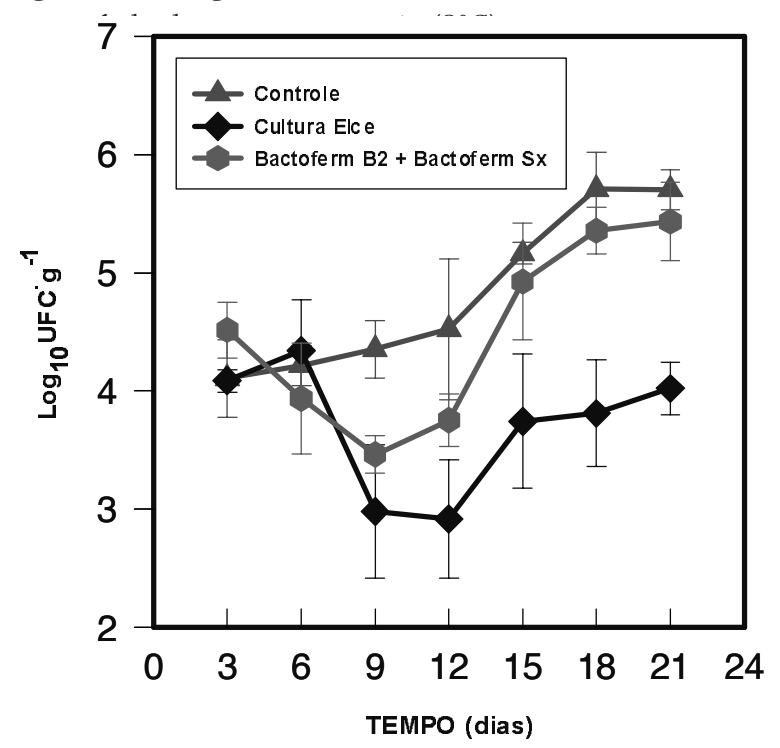

FIGURA 3. Contagem de bactérias Gram negativas de linguiça de frango, com ou sem a adição de culturas, durante o período de armazenamento $\left(8^{\circ} \mathrm{C}\right)$.

TERRA et al. [19] verificaram uma redução de 3 ciclos logaritmicos na contagem de coliformes totais em lingüiça suina adicionada da cultura Elce, ao final de quatro semanas de estocagem sob refrigeração $\left(2^{\circ} \mathrm{C}\right)$. 
As culturas bioprotetoras adicionadas à massa das lingüiças, proporcionam maior decréscimo no pH (Figura 4) das lingüiças de frango durante o seu período de armazenamento, quando comparadas ao controle. Segundo ADAMS \& MOSS [1], o pH mais elevado significa um maior desenvolvimento microbiano, determinando que as alterações apareçam mais rápido. Desta forma o decréscimo no $\mathrm{pH}$ proporcionado pelas culturas bioprotetoras contribuiu para a melhora da qualidade microbiológica da lingüiça de frango.

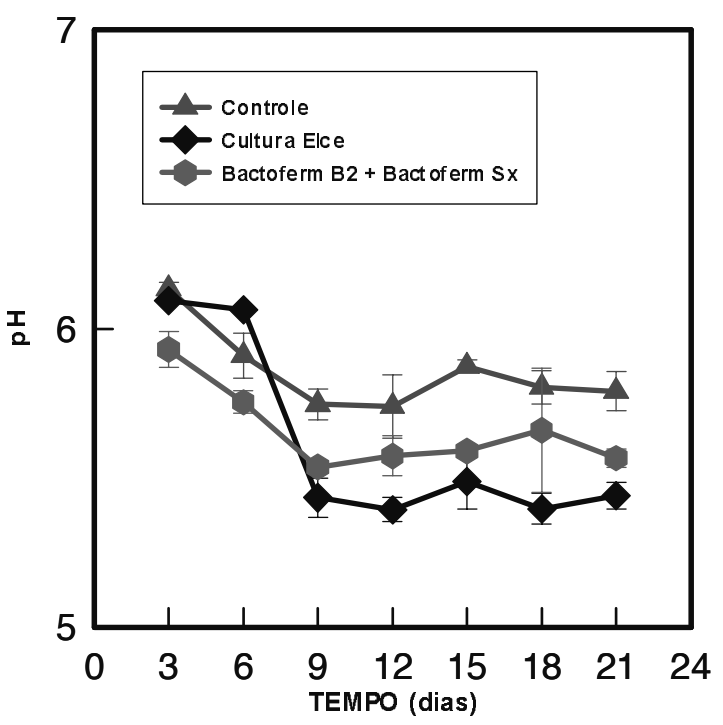

FIGURA 4. Determinação do pH de lingüiça de frango, com ou sem a adição de culturas, durante o período de armazenamento $\left(8^{\circ} \mathrm{C}\right)$.

$\mathrm{O}$ pH da lingüiça além de exercer influência direta sobre sua conservação, está diretamente relacionado a sua coloração e sabor. O pH deve ser suficientemente ácido para facilitar a produção de óxido de nitrogênio a partir do nitrito que combinado com a mioglobina produzirá a coloração rósea típica da lingüiça [4, 6].

A adição da cultura Elce e da Bactoferm B2 mais a Bactoferm S-Sx melhoraram as características sensoriais das lingüiças de frango cruas as quais mantiveram-se em melhores condições, por um período maior. Quanto a cor, as lingüiças cruas e cozidas não diferiram estatisticamente entre si até o $12^{\circ}$ dia. A partir do 15임 dia, as culturas starters proporcionaram melhora na cor das lingüiças cruas (Tabela 2). A melhora da cor não é uma conseqüência somente do abaixamento do $\mathrm{pH}$ proporcionado pelo Lactobacillus sake e Pediococcus pentosaceus, presentes na cultura Elce e pelo Lactobacillus alimentarius do Bactoferm B2, mas também pela enzima nitrato redutora do Staphylococcus xylosus (presente na cultura Elce e Bactoferm S-Sx) e do Staphylococcus carnosus da cultura Elce [20]. Em relação ao aroma, pode-se observar que as lingüiças cruas tratadas com as culturas lácticas apresentaram notas superiores às do controle a partir do 12 응 dia de armazenamento, sendo que somente no $21^{\circ}$ dia foi observado uma diferença estatística significativa entre as amostras controle e aquelas adicionadas de culturas com nota de 4,91 e 6,71, respectivamente (Tabela 3). A levedura Debaryomyces hansenii que é integrante da cultura Elce possui poder aromatizante sendo responsabilizada pela melhora no aroma da lingüiça através da ação de enzimas proteoliticas e lipoliticas.

TABELA 2. Média das notas atribuídas a cor das lingüiças de frango controle e das adicionadas de culturas bioprotetoras, durante o período de armazenamento sob refrigeração $\left(+8^{\circ} \mathrm{C}\right)$.

\begin{tabular}{|c|c|c|c|c|c|c|c|}
\hline $\begin{array}{l}\text { PERIOODO } \\
\text { DE ARMAZENAMENTO }\end{array}$ & $3^{\circ} \mathrm{DIA}$ & $6^{\circ} \mathrm{DIA}$ & $9^{\circ} \mathrm{DIA}$ & $12^{\circ} \mathrm{DIA}$ & $15^{\circ} \mathrm{DIA}$ & $18^{\circ} \mathrm{DIA}$ & $21^{\circ} \mathrm{DIA}$ \\
\hline \multicolumn{8}{|l|}{ LINGÜIÇA ASSADA } \\
\hline Controle & $8,47^{a}$ & $8,00^{\mathrm{a}}$ & $8,35^{\mathrm{a}}$ & $7,64^{\mathrm{a}}$ & $6,98^{\mathrm{a}}$ & $7,64^{\mathrm{a}}$ & $7,50^{\mathrm{a}}$ \\
\hline Elce & $8,50^{\mathrm{a}}$ & $7,71^{a}$ & $7,57^{\mathrm{a}}$ & $7,98^{a}$ & $6,64^{a}$ & $8,14^{\mathrm{a}}$ & $7,78^{a}$ \\
\hline $\begin{array}{l}\text { Bactoferm B2+Bactoferm } \\
\text { S-Sx }\end{array}$ & $8,28^{a}$ & $7,21^{a}$ & $7,92^{\mathrm{a}}$ & $7,58^{\mathrm{a}}$ & $6,80^{\mathrm{a}}$ & $7,71^{\mathrm{a}}$ & $7,71^{\mathrm{a}}$ \\
\hline \multicolumn{8}{|l|}{ LINGÜIÇA CRUA } \\
\hline Controle & $7,50^{\mathrm{a}}$ & $7,57^{\mathrm{a}}$ & $7,42^{\mathrm{a}}$ & $6,92^{a}$ & $5,14^{a}$ & $5,85^{\mathrm{a}}$ & $4,92^{\mathrm{a}}$ \\
\hline Elce & $8,21^{\mathrm{ab}}$ & $7,50^{\mathrm{a}}$ & $7,35^{\mathrm{a}}$ & $7,70^{\mathrm{a}}$ & $6,48^{b}$ & $7,50^{b}$ & $6,64^{\mathrm{b}}$ \\
\hline $\begin{array}{l}\text { Bactoferm B2+Bactoferm } \\
\text { S-Sx }\end{array}$ & $8,42^{b}$ & $7,88^{\mathrm{a}}$ & $7,14^{\mathrm{a}}$ & $7,92^{\mathrm{a}}$ & $6,61^{b}$ & $7,78^{\mathrm{b}}$ & $6,85^{\mathrm{b}}$ \\
\hline
\end{tabular}
- Mediar a lingüiça assada e a crua separadamente.

TABELA 3. Média das notas atribuídas ao aroma das lingüiças de frango controle e das adicionadas de culturas bioprotetoras, durante o período de armazenamento sob refrigeração $\left(+8^{\circ} \mathrm{C}\right)$.

\begin{tabular}{lcccccccc}
\hline $\begin{array}{l}\text { PERIODO } \\
\text { DE ARMAZENAMENTO }\end{array}$ & $3^{\circ} \mathrm{DIA}$ & $6^{\circ} \mathrm{DIA}$ & $9^{\circ} \mathrm{DIA}$ & $12^{\circ} \mathrm{DIA}$ & $15^{\circ} \mathrm{DIA}$ & $18^{\circ} \mathrm{DIA}$ & $21^{\circ} \mathrm{DIA}$ \\
\hline LINGÜIÇA ASSADA & & & & & & & \\
Controle & $8,14^{\mathrm{a}}$ & $8,00^{\mathrm{a}}$ & $8,21^{\mathrm{a}}$ & $7,50^{\mathrm{a}}$ & $7,64^{\mathrm{a}}$ & $7,42^{\mathrm{a}}$ & $7,71^{\mathrm{a}}$ \\
Elce & $8,35^{\mathrm{a}}$ & $7,77^{\mathrm{a}}$ & $8,00^{\mathrm{a}}$ & $7,84^{\mathrm{a}}$ & $7.00^{\mathrm{a}}$ & $7,57^{\mathrm{a}}$ & $7,41^{\mathrm{a}}$ \\
$\begin{array}{l}\text { Bactoferm B2+Bactoferm } \\
\text { S-Sx }\end{array}$ & $7,85^{\mathrm{a}}$ & $7,35^{\mathrm{a}}$ & $8,21^{\mathrm{a}}$ & $7,50^{\mathrm{a}}$ & $7,10^{\mathrm{a}}$ & $7,85^{\mathrm{a}}$ & $7,78^{\mathrm{a}}$ \\
\hline $\begin{array}{l}\text { LINGÜIÇA CRUA } \\
\text { Controle }\end{array}$ & $8,14^{\mathrm{a}}$ & $7,62^{\mathrm{a}}$ & $7,64^{\mathrm{a}}$ & $6,92^{\mathrm{a}}$ & $6,37^{\mathrm{a}}$ & $5,78^{\mathrm{a}}$ & $4,91^{\mathrm{a}}$ \\
Elce & $8,07^{\mathrm{a}}$ & $7,50^{\mathrm{a}}$ & $7,64^{\mathrm{a}}$ & $7,98^{\mathrm{a}}$ & $6,50^{\mathrm{a}}$ & $7,21^{\mathrm{a}}$ & $6,71^{\mathrm{b}}$ \\
$\begin{array}{l}\text { Bactoferm B2+Bactoferm } \\
\text { S-Sx }\end{array}$ & $8,35^{\mathrm{a}}$ & $7,20^{\mathrm{a}}$ & $7,35^{\mathrm{a}}$ & $8,07^{\mathrm{a}}$ & $6,64^{\mathrm{a}}$ & $7,28^{\mathrm{a}}$ & $6,71^{\mathrm{b}}$ \\
\hline
\end{tabular}

- Médias com a mesma letra na vertical não apresentam diferença significativa. Considerar a lingüiça assada e a crua separadamente.

As amostras cruas tratadas com ambas as culturas apresentaram notas superiores as do controle para a aparência, diferindo significativamente a partir do 15응 dia, embora a Bactoferm B2 + Bactoferm S-Sx não diferiram do controle no $21^{\circ}$ dia (Tabela 4).

As alterações das características sensoriais da lingüiça são resultado da ação dos microrganismos indesejáveis presentes. A lingüiça é um embutido com elevada atividade de água, portanto se constitui em um meio propício ao rápido desenvolvimento destes microrganis- 
mos. Considerando as notas atribuidas pelos provadores para as lingüiças cruas verifica-se uma redução significativa na qualidade sensorial das lingüiças controle. Já os lotes de lingüiças adicionadas das culturas bioprotetoras apresentaram-se com a qualidade sensorial mais estável, isto é apresentaram menor queda nas notas do início para o final do período de armazenamento. Depois de serem assadas essas diferenças não foram observadas pelos avaliadores (Tabelas 1, 2 e 3).

TABELA 4. Média das notas atribuídas a aparência das lingüiças de frango controle e das adicionadas de culturas bioprotetoras, durante o período de armazenamento sob refrigeração $\left(+8^{\circ} \mathrm{C}\right)$.

\begin{tabular}{|c|c|c|c|c|c|c|c|}
\hline $\begin{array}{l}\text { PERIOODO } \\
\text { DE ARMAZENAMENTO }\end{array}$ & $3^{\circ} \mathrm{DIA}$ & $6^{\circ} \mathrm{DIA}$ & $9^{\circ} \mathrm{DIA}$ & $12^{\circ} \mathrm{DIA}$ & $15^{\circ} \mathrm{DIA}$ & $18^{\circ} \mathrm{DIA}$ & $21^{\circ} \mathrm{DIA}$ \\
\hline \multicolumn{8}{|l|}{ LING ÜIÇA ASSADA } \\
\hline Controle & $8,07^{a}$ & $7,77^{\mathrm{a}}$ & $7,92^{\mathrm{a}}$ & $7,71^{a}$ & $7,17^{\mathrm{a}}$ & $7,57^{\mathrm{a}}$ & $7,50^{\mathrm{a}}$ \\
\hline Elce & $8,50^{a}$ & $7,50^{\mathrm{a}}$ & $7,71^{a}$ & $8,34^{a}$ & $6,50^{\mathrm{a}}$ & $7,78^{\mathrm{a}}$ & $7,64^{a}$ \\
\hline $\begin{array}{l}\text { Bactoferm B2+Bactoferm } \\
\text { S-Sx }\end{array}$ & $8,28^{a}$ & $7,70^{a}$ & $8,00^{a}$ & $7,82^{\mathrm{a}}$ & $6,85^{a}$ & $7,85^{\mathrm{a}}$ & $7,78^{a}$ \\
\hline \multicolumn{8}{|l|}{ LINGÜIÇA CRUA } \\
\hline Controle & $7,85^{a}$ & $7,71^{\mathrm{a}}$ & $7,50^{\mathrm{a}}$ & $6,77^{\mathrm{a}}$ & $5,28^{a}$ & $5,78^{a}$ & $4,92^{\mathrm{a}}$ \\
\hline Elce & $8,21^{a}$ & $7,42^{\mathrm{a}}$ & $7,35^{\mathrm{a}}$ & $7,71^{\mathrm{a}}$ & $6,62^{b}$ & $8,00^{b}$ & $6,71^{\mathrm{b}}$ \\
\hline $\begin{array}{l}\text { Bactoferm B2+Bactoferm } \\
\text { S-Sx }\end{array}$ & $8,42^{a}$ & $7,81^{a}$ & $7,07^{\mathrm{a}}$ & $7,64^{a}$ & $6,78^{b}$ & $7,14^{\mathrm{b}}$ & $6,57^{\mathrm{ab}}$ \\
\hline
\end{tabular}

RODRIGUES [16] verificou que a adição da cultura Elce em lingüiça frescal melhorou suas qualidades sensoriais, destacando-se o sabor que sofreu variações minimas nas notas durante a estocagem. No presente experimento os provadores não observaram diferenças significativas, para o sabor e textura, entre as lingüiças de frango controle e as adicionadas das culturas bioprotetoras (Tabela 5). Provavelmente os condimentos empregados na elaboração destas lingüiças tenham mascarado alguma possivel diferença existente entre as amostras, dificultando desta forma sua detecção pelos avaliadores.

Estudos de TERRA et al. [19] mostraram a importância do uso de Starters em lingüiças de carne suina, ao utilizar a cultura Elce, pois obtiveram aumento na vida útil do embutido e melhora considerável em seus atributos sensoriais como cor, aroma e sabor.

Nas amostras de lingüiças de frango utilizadas neste experimento não ocorreu o desenvolvimento de Staphylococcus aureus e Clostrídios ou Clostridia sulfito redutores (dados não apresentados).

Pelos resultados obtidos neste experimento pode-se constatar que a adição das culturas bioprotetoras nas lingüiças de frango além de melhorar sua qualidade sensorial, demonstraram ação antimicrobiana, sendo que a cultura Elce mostrou-se estatisticamente $(p>0,05)$ mais eficiente no controle do desenvolvimento de bactérias
Gram negativas. Desta forma, além de termos uma lingüiça de frango mais atraente, temos também um produto com maior segurança microbiológica.

TABELA 5. Média das notas atribuídas ao sabor e textura das lingüiças de frango assadas( controle e adicionadas de culturas bioprotetoras), durante o período de armazenamento sob refrigeração $\left(+8^{\circ} \mathrm{C}\right)$.

\begin{tabular}{|c|c|c|c|}
\hline $\begin{array}{l}\text { PERÍODO } \\
\text { DE ARMAZENAMENTO }\end{array}$ & $3^{\circ} \mathrm{DIA}$ & $6^{\circ} \mathrm{DIA}$ & $9^{\circ} \mathrm{DIA}$ \\
\hline \multicolumn{4}{|l|}{ SABOR } \\
\hline Controle & $8,50^{a}$ & $8,64^{a}$ & $7,57^{\mathrm{a}}$ \\
\hline Elce & $8,21^{a}$ & $8,07^{a}$ & $7,71^{a}$ \\
\hline $\begin{array}{l}\text { Bactoferm B2+Bactoferm } \\
\text { S-Sx }\end{array}$ & $8,21^{a}$ & $7,71^{a}$ & $7,85^{a}$ \\
\hline \multicolumn{4}{|l|}{ TEXTURA } \\
\hline Controle & $8,18^{a}$ & $7,92^{\mathrm{a}}$ & $7,85^{a}$ \\
\hline Elce & $8,28^{a}$ & $7,78^{a}$ & $7,95^{a}$ \\
\hline $\begin{array}{l}\text { Bactoferm B2+Bactoferm } \\
\text { S-Sx }\end{array}$ & $8,18^{a}$ & $7,71^{a}$ & $7,92^{\mathrm{a}}$ \\
\hline
\end{tabular}

- Médias com a mesma letra na vertical não apresentam diferença significativa.

\section{4 - CONCLUSÕES}

Pelos resultados apresentados e considerando as condições utilizadas neste experimento pode-se concluir que: a cultura Elce proporcionou inibição do desenvolvimento de microrganismos Gram negativos, enquanto que a adição do Bactoferm B2 e Bactoferm S-Sx proporcionou pequena inibição durante o período de armazenamento das lingüiças de frango. Estas culturas bioprotetoras proporcionaram maior decréscimo no $\mathrm{pH}$ das lingüiças de frango tratadas, quando comparadas com as controle. As caracteristicas sensoriais das lingüiças tratadas com as culturas starters foram significativamente diferentes $(\mathrm{p}<0,05)$ do controle a partir do 15응 ou $21^{\circ}$ dia de armazenamento, conforme o parâmetro avaliado. Os provadores não observaram diferenças significativas nas características sensoriais das lingüiças após terem sido assadas.

\section{5 - REFERÊNCIAS}

[1] ADAMS, M. R.; MOSS,M.O. 1997. Microbiologia de los Alimentos. España: Acribia, 464 p.

[2] BRASIL, 1981. Ministério da Agricultura e Reforma Agrária. Laboratório Nacional de Referência Animal - LANARA. Métodos analíticos oficiais para controle de produtos de origem animal e seus ingredientes - Métodos Físicos e Químicos. Brasília.

[3] BRASIL, 1993. Portaria № 101, Métodos analíticos para controle de produtos de origem animal e seus ingredientes - Métodos Microbiológicos. Diário Oficial [da República Federativa do Brasil] , (156), seção I: 11937-11960.

[4] COVENTRY, J.; HICKEY, M. W. 1991. Growth characteristics of meat starters cultures. Meat Sci., 29(30): 41-48. 
[5] FRANCO, B. D. G. M.; LANDGRAF, M. 1996. Microbiologia dos alimentos, São Paulo: Atheneu, 182 p.

[6] HAMMES, W. P.; BANTLEON, A.; Min, S. 1990. Lactic acid bacteria in meat fermentation. FEMS Microbiol. Rev., (87): 165- 174.

[7] HAMMES, W. P.; KNAUF, H. J. 1994. Starters in the Processing of Meat Products. Meat Sci. (36):155-168.

[8] HARRIGAN, W. F. 1998. Laboratory Methods in Food Microbiology. $3^{\text {rd }}$ ed., San Diego, California: Academic Press, $532 \mathrm{p}$.

[9] HOOFFMANN, F. L.; GARCIA-CRUZ, C. H.; GODOY, J. H. F.; VINTURIM, T. M. 1996. Análise microbiológica e sensorial de lingüiça de frango produzida artesanalmente. B. CEPPA, Curitiba, 14 (1):49-58.

[10] KRÖCKEL, L. 1999. Natural barriers for use in biopreservation. Fleischwirtschaft Int., 2 (99): 36-38.

[11] MANHOSO, F. F. R. 1996. Aspectos químicos e microbiológicos das lingüiças tipo frescal no Brasil. Rev. Nac. da Carne, (230): 90-92.

[12] MONTVILLE, T. J.; WINKOWSKI, K. 1997. Biologically based preservation systems and probiotic bactéria. In: Doyle, M. P. Beuchat, L. R., Montville, T. J.(eds.) Food Microbiol. Washington D.C.: ASM Press., p. 557-577.
[13] MORAES, M. A. C. 1993. Métodos para avaliação sensorial dos alimentos. Campinas: Editora da UNICAMP, $93 \mathrm{p}$.

[14] PRICE, J. F.; SCHWEIGERT, B. S. 1994. Ciência de la carne y de los produtos cárnicos. Zaragoza, España: Acribia, 581p.

[15] PROUDLOVE, R. K. 1996. Os alimentos em debate: Uma visão equilibrada, São Paulo: Livraria Varela, 251 p.

[16] RODRIGUES, R. A. 1998. Conservantes naturais no processamento de Lingüiça frescal. Dissertação de mestrado - Departamento de Tecnologia e Ciência dos alimentos, Universidade Federal de Santa Maria, 91 p.

[17] SIQUEIRA, R. S. 1995. Manual de microbiologia de alimentos. EMBRAPA. Centro Nacional de Pesquisa e Tecnologia Agro-industrial de Alimentos (Rio de Janeiro, RJ) Brasília: EMBRAPA-SPI, 159 p.

[18] TERRA, N. N. 1998. Apontamentos de tecnologia de carnes. São Leopoldo: Ed. UNISINOS, 216 p.

[19] TERRA, N. N.; ABREU, R.; VALENTE, C. R.; TERRA, L. M. 1995. A cultura Starter na fabricação da lingüiça. Revista Nacional da Carne. (225): 73-77.

[20] WEBER, H. 1994. Dry sausage manufature. Fleischwirtschaft. 3(74): 278-281. 